\title{
An Improved Earned Value Analysis Tool for Mitigating Progress Risks in Long Duration Projects
}

\author{
Ali Fayad $^{1}$, Bassam Hussein ${ }^{2}$, Elie Maalouf ${ }^{2}$, Amin Haj-Ali $^{3 \dagger}$ \\ ${ }^{1}$ Lebanese International University, Department of Industrial Engineering, Beirut, Lebanon \\ ${ }^{2}$ International University of Beirut, Department of Industrial Engineering, Beirut, Lebanon \\ ${ }^{3}$ Lebanese International University, Department of Computer and Communications Engineering, \\ Beirut, Lebanon \\ ${ }^{\dagger}$ Corresponding author: amin.hajali@liu.edu.lb
}

\begin{abstract}
As a risk control tool, earned value analysis is crucial for identifying risky trends in the budget or schedule of a project. This tool relies on earned value management, a method for calculating cost and schedule variances. However, this method does not take into account the time value of money. This in itself is a threat that could lead to misleading data and eventually wrong decisions. This paper explores the risk management process, the earned value management method, and proposes a methodology that compliments the earned value management method with net present value calculations. This will allow project managers to take sound decisions based on more accurate information.
\end{abstract}

\section{Introduction}

The Project Management Institute (PMI) divides project management into ten knowledge areas, one of which is project risk management. Under this knowledge area, best practices are suggested to manage project risks. The risk management process involves the following steps [1]:

- Risk identification

- Risk assessment: qualitative and/or quantitative assessment

- $\quad$ Risk response planning

- Risk control

Another important aspect of project management involves tracking, monitoring and controlling project progress through the schedule and budget. This is done through earned value analysis. In addition to its importance as a progress control tool, the earned value analysis may be considered as a risk control tool.

This paper will briefly cover the risk management process and introduce an evolved earned value analysis that would contribute to the mitigation of project risks. 


\section{Risk Management Processes}

The first step in risk management is identifying risks. Risks can be either opportunities (positive risks) or threats (negative risks). After they are identified, risks are analyzed both qualitatively and quantitatively. Under qualitative assessment, a risk probability and impact matrix is developed for both threats and opportunities. This matrix is used to classify risks as low, moderate or high depending on the organization's risk profile. Figure 1 below shows an example of a probability and impact matrix. It classifies risks from low to high using color-coding; green being low, amber being moderate and red being high. This classification is used as a priority system for dealing with risks.

\begin{tabular}{|c|c|c|c|c|c|c|c|c|c|c|}
\hline Probability & \multicolumn{5}{|c|}{ Threats } & \multicolumn{4}{c|}{ Opportunities } \\
\hline $\begin{array}{c}0.90 \\
\text { Very Likely }\end{array}$ & 0.05 & 0.09 & 0.18 & 0.38 & 0.72 & High & High & High & Med & Low \\
\hline $\begin{array}{c}0.70 \\
\text { Likely }\end{array}$ & 0.04 & 0.07 & 0.14 & 0.28 & 0.56 & High & High & Med & Med & Low \\
\hline $\begin{array}{c}0.50 \\
\text { Possible }\end{array}$ & 0.03 & 0.05 & 0.10 & 0.12 & 0.40 & High & High & Med & Low & Low \\
\hline $\begin{array}{c}0.30 \\
\text { Unlikely }\end{array}$ & 0.02 & 0.03 & 0.06 & 0.12 & 0.24 & High & Med & Med & Low & Low \\
\hline $\begin{array}{c}0.10 \\
\text { Very Unlikely }\end{array}$ & 0.01 & 0.01 & 0.02 & 0.04 & 0.08 & Med & Low & Low & Low & Low \\
\hline & 0.05 & 0.10 & 0.20 & 0.40 & 0.80 & $\begin{array}{c}\text { Very } \\
\text { High }\end{array}$ & High & Med. & Low & $\begin{array}{l}\text { Very } \\
\text { Low }\end{array}$ \\
\cline { 2 - 10 } & \multicolumn{3}{|c|}{ Example Impact Definitions - May Be Tailored to Each Project Objective } \\
Impact on an Objective (e.g. Cost, Schedule, Scope, Quality)
\end{tabular}

Fig. 1: Probability and Impact Matrix

The next step is quantitative assessment, determining the probability of occurrence and the impact of each risk. The probability and impact are then multiplied to obtain a risk value and be classified according to the probability and impact matrix.

Risk response planning identifies the response for each risk based on its priority, the available resources, schedule and other factors. The five available strategies for negative risks are: avoiding, transferring, sharing, mitigating and accepting the risk. Finally, the process of risk control is performed through implementing risk response plans, tracking identified risks, identifying new risks, etc. One of the tools used in controlling risk is the earned value analysis, which analyses the variances in the budget and schedule of a project and identifies future trends based on the current performance. This will allow the project manager to predict potential risks of falling behind schedule or exceeding the budget or vice-versa, and take advantage of the emerging opportunity.

\section{Earned Value Analysis}

The earned value analysis (EVA) is a quantitative project management technique that evaluates project performance and predicts final project results. The project performance evaluation is done using the earned value management method (EVM). EVM is a methodology for measuring project performance using an integrated schedule and budget based on the project work breakdown structure [2]. The earned value management relies on three main inputs: 
- $\quad$ Planned Value (PV): the authorized budget assigned for the work to accomplish a scheduled activity. The sum of PV's for all activities in the project is called the budget at completion (BAC), or baseline budget [1].

- Actual Cost (AC): the cost incurred to accomplish the activity or work package during a specific time period. In other words, it's the cost of the accomplished work [1].

- $\quad$ Earned Value (EV): the budget associated with the authorized work that has been completed for an activity. It is a measure of the work performed expressed in terms of the budget authorized for that work [2]. It is calculated using the formula [1]:

$$
\mathrm{EV}=\% \text { complete } \times \mathrm{PV}
$$

Table 1 below summarizes the rest of the metrics used in earned value management.

Table 1: EVM Metrics

\begin{tabular}{|l|l|l|}
\hline Metric & Definition & Equation \\
\hline Cost Variance & $\begin{array}{l}\text { Measure the budget performance } \\
\text { expressed as the difference between } \\
\text { the earned value and the actual cost at } \\
\text { a specific point in time during the } \\
\text { project }\end{array}$ & CV $=\mathrm{EV}-\mathrm{AC}$ \\
\hline Schedule Variance & $\begin{array}{l}\text { Measures the schedule performance } \\
\text { expressed as the difference between } \\
\text { the earned value and the planned } \\
\text { value at a specific point in time } \\
\text { during the project }\end{array}$ & \\
\hline $\begin{array}{l}\text { Cost Performance } \\
\text { Index }\end{array}$ & $\begin{array}{l}\text { Indicates the cost efficiency for the } \\
\text { earned work. PMI considers the CPI } \\
\text { as the most critical EVM metric }\end{array}$ & CPI = EV / AC \\
\hline $\begin{array}{l}\text { Schedule } \\
\text { Performance Index }\end{array}$ & \begin{tabular}{l} 
Indicates the schedule efficiency. \\
\hline
\end{tabular} & SPI = EV / PV \\
\hline
\end{tabular}

Figure 2 shows a graph of the $\mathrm{PV}, \mathrm{AC}$ and $\mathrm{EV}$ for a certain project [2].

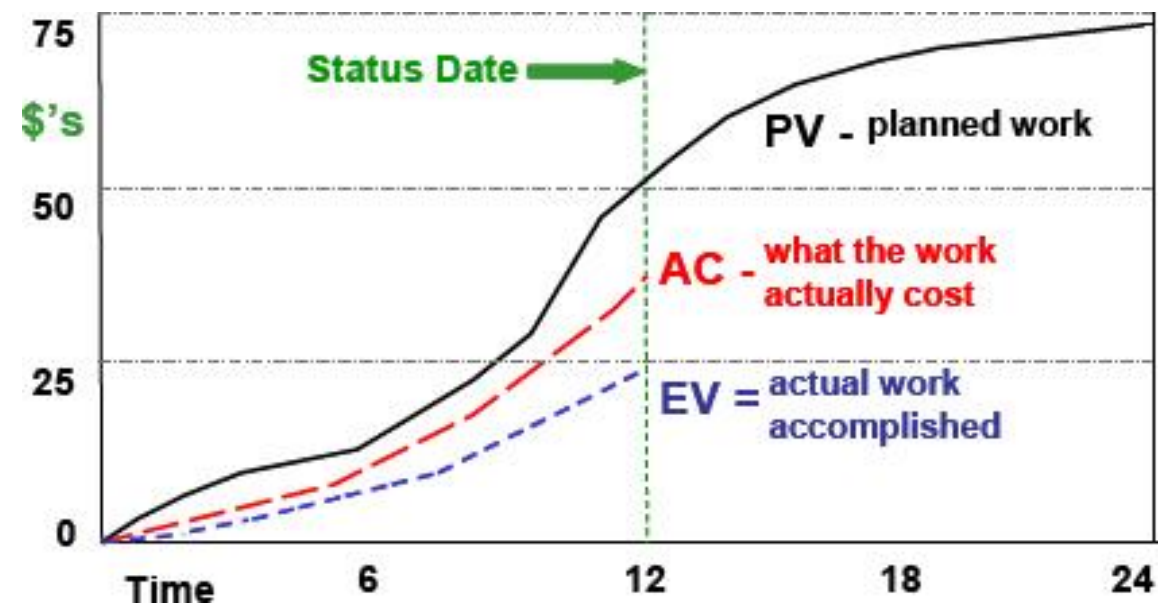

Figure 2: Earned Value, Planned Value, and Actual Cost 
At time period 12, the earned value of the work is less than the planned value and the actual cost. This means that this project has negative SV and CV.

This method is great for monitoring schedule and cost performance by calculating schedule and cost variances. However, it has one shortcoming: it does not take into consideration the time value of money. By ignoring this fact, we run a risk of obtaining misleading data, which could lead to bad decisions especially in projects that span over a duration of 3 or more years.

\section{Risk Management Process applied on Current EVA}

The current unadjusted EVA presents a threat on the project. The threat is obtaining misleading forecasts and subsequently making bad decisions.

On a scale of 0.1 to 1 , the likelihood of this threat happening is 1 while the impact is 0.5 , which makes the risk value 0.5 . According to the probability and impact matrix used in figure 2, this threat would be classified as high.

The risk response depends on the cause of the threat. In this case, the cause of obtaining misleading forecasts is ignoring the time value of money. Therefore the proper risk response is to mitigate it by using an adjusted method to perform EVM that takes the time value of money into consideration. This mitigation will bring down the likelihood of the threat from 1 to 0.1 , which will in turn bring down the risk value to 0.05 .

The EVM with time value of money consideration is discussed in detail in the next section.

\section{Proposed Methodology}

The time value of money is the idea that money available at the present time is worth more than the same amount available in the future [3]. In other words, the time value of money is the inflation of the currency. There are rare instances where this might not be the case when there is deflation, but this is not within the scope of this paper. From an engineering economics perspective, if two amounts of money are to be compared, the correct way is have them compared during the same time period.

Looking back at figure 2, do the PV, the EV and the AC belong to the same period? The answer is no because the PV was estimated during time 0, while EV and $\mathrm{AC}$ were obtained during time period 12. During this period, the currency used might have lost part of its value so the comparison will not be accurate.

In order to correct this, the equivalent amounts of the three sums should be calculated in the same time period then compared. The following equation is used to find the future worth of a sum of money P [4]:

where:

$$
F=P \cdot(1+i)^{n}
$$

P: the present value

i: interest rate
F: the future value

n: number of time periods 
Equation (1) is derived from the net present value method and is used to calculate the future value of any sum of money assuming a constant discount rate. In reality, each year will have a different inflation rate. To correct this, equation (2) should be used:

where:

$$
F=P \cdot \prod_{i=1}^{t}\left(1+k_{i}\right)
$$

$\mathrm{k}_{\mathrm{i}}$ : inflation rate in year $\mathrm{i}$

t: total number of years

Using equation (2), a different inflation rate for each year can be used $\left(\mathrm{k}_{\mathrm{i}}\right)$. $\mathrm{i}=1$ is the first year and $\mathrm{i}=\mathrm{t}$ is the current year during which the EVM is being performed.

In order to demonstrate the proposed EVM method, a simple numerical example will be shown. Table 2 shows the inflation rates in Lebanon between the years 2006 and 2010.

Table 2: Inflation Values in Lebanon [4]

\begin{tabular}{|c|c|}
\hline Year & Inflation Rate \\
\hline 2006 & $5.6 \%$ \\
\hline 2007 & $4.1 \%$ \\
\hline 2008 & $10.8 \%$ \\
\hline 2009 & $1.2 \%$ \\
\hline 2010 & $4.0 \%$ \\
\hline
\end{tabular}

The inflation values in Table 2 will be used to calculate the variances using the proposed EVM method. Table 3 shows the details of the calculations.

Table 3: EVM Calculations Example

\begin{tabular}{|c|c|c|c|c|c|c|c|}
\hline & PV (LBP) & AC (LBP) & EV (LBP) & SV (LBP) & SPI & CV (LBP) & CPI \\
\hline $\begin{array}{c}\text { Classical } \\
\text { EVM }\end{array}$ & $20,000,000$ & $26,000,000$ & $17,000,000$ & $-3,000,000$ & 0.85 & $-9,000,000$ & 0.65 \\
\hline $\begin{array}{c}\text { Corrected } \\
\text { EVM }\end{array}$ & $25,638,833$ & $26,000,000$ & $21,793,008$ & $-3,845,825$ & 0.85 & $-4,206,992$ & 0.84 \\
\hline $\begin{array}{c}\% \\
\text { Difference }\end{array}$ & $22 \%$ & $0 \%$ & $22 \%$ & $22 \%$ & $0 \%$ & $-114 \%$ & $22 \%$ \\
\hline
\end{tabular}

The calculations shown in Table 3 are for a project that started at the end of 2005 and is being analyzed at the end of 2010. As per the budget, the planned value for 2010 was 20,000,000 LBP, however, if the inflation rate is accounted for as per equation 2, the equivalent of the planned value (PV) in year 2010 becomes 25,638,833 LBP. The EVM metrics are calculated and the percentage difference between the classical EVM and corrected EVM is shown for each metric. The percentage difference between the PV, EV, SV and CPI of both methods is $22 \%$, while that of the CV is $114 \%$. Notice that the CV in the classical EVM is more than double that of the corrected EVM; and the CPI went up from 0.65 to 0.84 , which is much more reasonable.

Using the corrected EVM method should give more realistic performance measurements for the project and therefore should lead to better management decisions.

\section{Critical Assessment of the Proposed Methodology}


The proposed method of correcting for the time value of money necessitates that the equivalent of the PV, AC and EV be calculated in the current time of the EVM. Comparing all equivalent amounts during the same time period will decrease errors associated with the change in currency value. Since inflation in generally positive, the cost and schedule variances are usually exaggerated if the time value of money is not accounted for. As a result, management and stakeholders of a project will think the project is doing worse than it actually is. Basing future actions on such a flawed analysis will lead to bad decisions.

Within a project context, it is crucial to have all features, tools and artifacts fully integrated within the adapted project management information system (PMIS) [5]. Based on this recommendation, the proposed complementation of the EVM should be integrated within the PMIS in use such as MS Project, PRIMAVERA, Open Workbench or any other generic or proprietary system.

\section{Conclusion}

Earned value management is an excellent practice for monitoring project performance. One shortcoming is the disregard of the time value of money for long duration projects where inflation has a significant effect on the schedule and cost variances, especially in the later years of a project. A method was proposed to rectify this where the equivalent of any sum of money is calculated in the current time of the measurements so that the comparison is done in the same time period. This allows project managers to reflect the performance accurately and help in future decisions accordingly.

\section{References}

[1] Project Management Institute, $P M B O K$ Guide, 5th ed.: Project Management Institute, (2013).

[2] J. A. Lukas, "How to make earned value work on your project," in PMI Global Congress 2012, Vancouver, (2012).

[3] The Pennsylvania State University. MoneyCounts: A Penn State Financial Literacy Series. [Online]. https://psu.instructure.com/courses/1806581/modules

[4] Knoema. [Online]. https://knoema.com/atlas/Lebanon/Inflation-rate (2017)

[5] B. Hussein and A. Dayekh, "Business Process Reengineering (BPR) Key Success Factors," International Journal of Applied Management Sciences and Engineering (IJAMSE), vol. 1, no. 1, pp. 58-66, (2014).

[6] L. Blank and A. Tarquin, Engineering Economy, 7th ed., M. Lange, Ed. New York, USA: McGraw-Hill, (2012). 